\title{
La interfaz salud y medio ambiente en el diálogo com estudiantes: ressignificando el sentido del cuidado
}

\section{The interface health and environment in dialogue with students: resignifying the sense of care}

\section{A interface saúde e ambiente no diálogo com escolares: ressignificando o sentido do cuidado}

\author{
Silvana Ceolin¹, Marjoriê Mendieta², Márcia Vaz Ribeiro ${ }^{3}$, Márcio Rossato Badke ${ }^{4}$, \\ Teila Ceolin ${ }^{5}$, Rita Maria Heck ${ }^{6}$
}

${ }^{1}$ Mestre em Enfermagem. Doutoranda do Programa de Pós-Graduação em Enfermagem (PPG-Enf) da UFPel, em cotutela com a Universidad de Alicante.

${ }^{2}$ Mestre em Enfermagem. Doutoranda do Programa de Pós-Graduação em Enfermagem (PPG-Enf) da UFPel. ${ }^{3}$ Doutora em Fisiologia Vegetal. Pós-doutoranda do Programa de Pós-Graduação em Enfermagem (PPG-Enf) da UFPel.

${ }^{4}$ Mestre em Enfermagem. Doutorando do Programa de Pós-Graduação em Enfermagem (PPG-Enf) da UFPel. ${ }^{5}$ Doutora em Enfermagem. Professora da Faculdade de Enfermagem da UFPel.

${ }^{6}$ Doutora em Enfermagem. Professora do PPG-Enf da UFPel.

Cómo citar este artículo en edición digital: Ceolin, S.,, Mendieta, M.C.,, Ribeiro, M.V., Badke, M.R., Ceolin, T., \& Heck, T.R.M. (2017). La interfaz salud y medio ambiente en el diálogo com estudiantes: ressignificando el sentido del cuidado. Cultura de los Cuidados (Edición digital) 21,47. Recuperado de http://dx.doi.org/10.7184/cuid.2017.47.13

\section{Correspondencia: (Remitirse al correo electrónico) \\ Correo electrónico: silvanaceolin@gmail.com \\ Recibido: 23/07/2016; Aceptado: 20/11/2016}

Este trabalho recebeu fomento da Fundação de Amparo à Pesquisa do Estado do Rio Grande do Sul (FAPERGS).

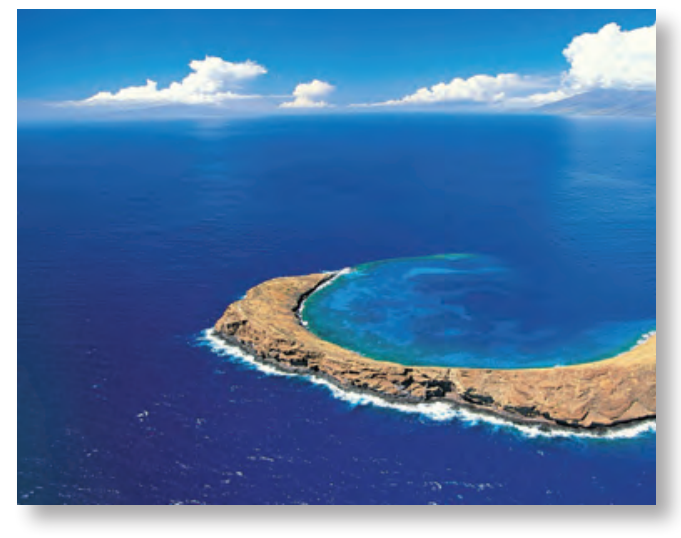

ABSTRACT

Objective: know the meanings produced by students from dialogues of health care and the environment. Methodology: a qualitative study with 65 students of two schools of the Pelotas /RS /Brazil. The data were collected from September to August/2011/2012. The material analyzed in this paper was produced at the end of 18 workshops from essays and speeches written by focus groups. Results: it was observed that the process of participation at the workshops created a close liaison between health care encompassing the human relationship with the environment. The dynamic provided the motivation for adopting collective conscious, ethical attitudes, gesture of citizenship and ressignification of the values and symbology, including in these medicinal plants. Conclusion: the health and environmental issues can be optimized and experienced in an enjoyable way when worked interconnected with the individual's culture.

Keywords: Nursing, health Education, medicinal plants, culture.

\section{RESUMEN}

Objetivo: discutir los significados producidos por escolares a partir de diálogos de cuidados de salud y el medio ambiente. Me- 
todología: estudio cualitativo con 65 alumnos de escuelas del municipio de Pelotas/RS/ Brazil. La recogida de datos se llevo a efecto de septiembre/2011 a agosto/2012. El material analizado es resultado de 18 talleres de grupos focales. Resultados: se observó que el proceso de participación en los talleres provocó un estrecho enlace entre la atención de la salud que abarca la relación humana con el medio ambiente. La dinámica proporciono la motivación para la adopción de actitudes conscientes, colectivas, éticas, ciudadanas, de resignificación de los valores y simbología, incluidos en estas plantas medicinales. Conclusión: la salud y el medio ambiente pueden ser optimizados y vividos de forma agradable cuando son convenientemente trabajados de manera relacional con la cultura de los individuos.

Palabras clave: Enfermería, educación en salud, plantas medicinales, cultura.

\section{RESUMO}

Objetivo: conhecer os significados produzidos por escolares a partir de diálogos sobre cuidado à saúde e ambiente. Metodologia: estudo de abordagem qualitativa com 65 educandos de duas escolas do município de Pelotas/RS/Brasil. Os dados foram coletados de setembro/2011 a agosto/2012, ao final de 18 oficinas, por meio de redações produzidas pelos escolares e grupo focal. Foi realizada análise de conteúdo temática. Resultados: observou-se que o processo de participação nas oficinas despertou uma vinculação estreita entre cuidado em saúde englobando a relação humana com o ambiente. A dinâmica oportunizou observar a motivação para adoção de atitudes conscientes, coletivas, éticas, cidadãs, de ressignificação dos valores e simbologias, incluindo nestas as plantas medicinais. Conclusões: os temas saúde e ambiente podem ser otimizados e vividos de forma prazerosa quando trabalhados de maneira interligada com a cultura dos indivíduos.

Palavras-chave: Enfermagem,, educação em saúde, plantas medicinais, cultura.

\section{INTRODUÇÃO}

$\mathrm{Na}$ atualidade, a interface saúde e ambiente vêm sendo cada vez mais discutida, devido à qualidade de vida estar associada ao equilíbrio socioambiental. A sustentabilidade envolve a sociedade, a educação, a política, a cultura, a arte, a natureza, o planeta e a vida de cada pessoa (Boff, 2012).

É neste sentido que o conceito de cuidado inclui certo modo de estar-no-mundo-com-os-outros e uma determinada práxis, preservadora da natureza. Representa uma relação amorosa, respeitosa e não agressiva para com a realidade, e por isso não destrutiva (Boff, 2012).

Em uma perspectiva interdisciplinar, o cuidado em saúde pode ser ressignificado por meio da educação. É nesse aspecto que a escola tem uma função social peculiar, pois as crianças/adolescentes estão em um período de formação de valores e em constante significação de seus conceitos (Ceolin, 2012).

O conceito de cultura nesse contexto é dinâmico, pois o sujeito traz suas experiências do cuidado familiar/comunitário e compartilha conhecimentos, símbolos e significados no processo educativo, fortalecendo a sua criticidade e capacidade de reflexão (Geertz, 2011).

Estudos destacam a importância da parceria entre educação, saúde e ambiente no contexto escolar, pois fortalece a construção de uma postura protagonista do educando no cuidado ao ambiente em que vive (Alves, 2015; Lima, Miranda, 2016; Amaral, 2016; Souza, Santos, 2016 Ceolin et al.,2016). Estas 
proposições levaram ao seguinte questionamento: Quais são os significados produzidos por escolares mediante diálogos sobre cuidado à saúde e ambiente?

Nesta perspectiva, o objetivo deste estudo foi conhecer os significados produzidos por escolares a partir de diálogos sobre cuidado à saúde e ambiente.

\section{METODOLOGIA}

Estudo qualitativo, exploratório e descritivo (Minayo, 2015), vinculado ao projeto de pesquisa "Uso de plantas medicinais e as práticas populares de saúde entre escolares da região Sul do Rio Grande do Sul', o qual integra o Programa Novos Talentos da Coordenação de Aperfeiçoamento de Pessoal de Nível Superior (CAPES), edital no 055/2012. Foi desenvolvido em duas escolas públicas da região periférica da cidade de Pelotas/RS/Brasil. As atividades envolveram 28 escolares matriculados no 50 ano de uma escola estadual, 26 escolares matriculados no 5 o ano e 29 no 6 o ano de uma escola municipal, perfazendo, neste primeiro momento, 83 alunos matriculados no ano letivo de 2011. Na primeira etapa, foram realizadas 18 oficinas (seis por turma), das quais, seis no espaço escolar e doze nas dependências da Faculdade de Enfermagem da Universidade Federal de Pelotas. As oficinas forma desenvolvidas no período de setembro a dezembro de 2011, coordenadas por três mestrandas e seis bolsistas de iniciação científica. Algumas atividades contaram também com convidados (um agrônomo e uma fisioterapeuta) que contribuíram para a interdisciplinaridade das discussões.

Foram abordadas questões sobre saúde, plantas medicinais e a relação do ser humano com o ambiente. Os recursos didáticos envolveram discussões em roda, cartazes, pinturas, jogo da memória, vídeos, atividades no Laboratório de Cuidado em Saúde e Plantas Bioativas de plantas e no Horto Didático de plantas medicinais.

A metodologia de operacionalização das oficinas foi alicerçada no referencial teórico de Clifford Geertz e Paulo Freire. Geertz (2011) diz que a cultura não é estática, mas construída pelos sujeitos ao interagirem no cotidiano. Para Freire (2011), os processos educativos devem ser mediados pelo diálogo ente às culturas, partindo das experiências concretas dos sujeitos e estimulando o movimento ação-reflexão-ação. No campo da saúde, a articulação desses autores fundamenta um processo de educação em saúde culturalmente sensível, no qual os agentes compartilham conhecimentos e fortalecem seus saberes e práticas em relação à prevenção e promoção da saúde.

Ao final destes seis encontros, foi solicitado que os escolares escrevessem uma redação a partir da seguinte questão norteadora: "O que as oficinas representaram na minha vida?". Dos 83 escolares participantes da pesquisa, 65 escreveram a redação e 30 participaram dos grupos focais, compondo a totalidade dos sujeitos da pesquisa.

$\mathrm{Na}$ segunda etapa da pesquisa, foram realizados três grupos focais, sendo um com cada turma, composto por 10 escolares elencados por sorteio aleatório. Esta atividade ocorreu nos meses de julho e agosto de 2012 e contou com a presença de um mediador, um observador e um responsável pela gravação. Os grupos focais foram realizados na Faculdade de Enfermagem da Universidade Federal de Pelotas, tendo duração de aproximadamente 50 minutos.

Os dados que emergiram das redações e dos grupos focais foram analisados por meio da proposta operativa de Minayo (2015), da 
qual emergiram três temas: $1^{\circ}$ ) diálogo sobre plantas medicinais (Ceolin et al., 2016); $2^{\circ}$ ) cuidado com a saúde; $3^{\circ}$ ) cuidado com o ambiente. Neste artigo serão abordados o segundo e o terceiro tema. Na discussão dos resultados apresentados, "texto escrito" refere-se às redações e "discurso oral", aos grupos focais.

$\mathrm{O}$ estudo seguiu as normas nacionais e internacionais de ética em pesquisa com seres humanos e foi aprovado pelo Comitê de Ética e Pesquisa da Faculdade de Medicina da Universidade Federal de Pelotas, protocolo 020/2011.

\section{RESULTADOS E DISCUSSÃO}

No que se refere à caracterização dos escolares, constatou-se que a idade destes variou entre 9 e 15 anos, com predomínio do sexo feminino (51\%). As duas escolas referidas neste estudo localizam-se em uma cidade do extremo Sul do Rio Grande do Sul/Brasil, numa região de alta vulnerabilidade social, com precárias condições de saúde, educação, renda, moradia e saneamento básico.

Os encontros com os escolares foram mediados por ações, reflexões e negociações integradas as suas realidades culturais. As oficinas abordaram discussões sobre poluição ambiental, reciclagem de materiais, cuidados com preservação dos recursos naturais e seus reflexos na saúde humana.

Observou-se que esses diálogos provocaram a discussão integrada entre natureza, cuidado e saúde, fomentando a consciência das crianças sobre esta relação, conforme emerge nos relatos a seguir:

"Eu estou adorando este projeto, porque este projeto faz as crianças cuidarem da natureza." (Canela, texto escrito)

"Eu acho que a gente tem que cuidar do ambiente, é bom para nós e os animais, é bom para nossa saúde." (Pulmonária, discurso oral)
"Cuidar do ambiente é bom pra vida na terra. Ajudar o planeta não poluindo, o solo se torna melhor, e através da fotossíntese as plantas liberam mais oxigênio para a vida." (Guaco, texto escrito)

Os escolares revelaram a preocupação com a conservação dos recursos naturais, e seus benefícios para a saúde. Perceberam também, a interdependência dos seres vivos com o ambiente e sua relação com a qualidade de vida.

A reflexão crítica do contexto em que se vive leva a interpretar as condições de vida e repensar possibilidades de promoção de um viver saudável. Deste modo, abrem-se caminhos para o fortalecimento de atitudes cidadãs, solidárias e críticas (Ceolin et al., 2016).

Fazendo uma aproximação com o pensamento de Paulo Freire, entende-se o sujeito como um ser inacabado, pois está sempre em um processo de construção sociocultural e histórico, que o modela como um ser singular. Logo, a cultura é um sistema simbólico fluido e aberto (Geertz, 2011) propiciando a incorporação ou o afastamento de práticas e crenças. Daí surge o desafio dos processos educativos dialógicos: motivar a geração do viver com um significado, integrado harmonicamente ao ambiente.

Neste pensar, a saúde integra diversos elementos, e a educação, quando interligada à cultura, permite a reconstrução da teia de significados que o ser humano produz para interpretar e conduzir suas práticas de cuidado de saúde de si e do mundo.

Em relação à comunidade em que vivem, observou-se que os educandos vislumbraram ações prejudiciais, conforme os relatos a seguir:

"A pessoas cortam árvores, botam fogo, isso acontece muito. Às vezes nem os animais se salvam." (Menta, discurso oral) 
"Muita gente joga lixo no bueiro. Quando chove, transborda, prejudica as casas de quem mora lá perto. E depois que chove ficam poças, e não tem como tu passar e não molhar o pé, aí pode causar aquela doença do rato, já ouvi vários casos." (Boldo, discurso oral)

"Muitas vezes não separam o lixo, isso faz mal pra saúde, para as florestas e para os animais." (Limoeiro, discurso escrito)

As falas dos escolares demonstram os problemas da comunidade em relação às ações dos moradores sobre o seu território. Estas possuem um impacto significativo na saúde, tornando o ambiente mais suscetível ao aparecimento de doenças.

Crianças que residem em locais que possuem, como costume, a desposição inadequada do lixo, podem acreditar que esta atitude seja algo natural. É nesse processo que se moldam os valores e crenças de uma população, ou seja, através dos modos de viver o cotidiano (Geertz, 2011). Por isso, a importância das atividades educativas, por meio das quais indivíduos e comunidades reflitam sobre ações, como produção de lixo, queimadas, desmatamento e seus reflexos no ambiente e saúde humana, tornando-se promotores de ações sustentáveis.

O pensamento crítico se instaura por meio da participação ativa e reflexiva dos estudantes no processo educativo. A construção desta participação incide sobre a relação horizontal entre os sujeitos, que precisa ser fundamentada no diálogo, para que ocorram trocas significativas de experiências e construção compartilhada de saberes (Freire, 2011).

O discurso apresentado pelos escolares foi aproximado de circunstâncias habituais, que, de acordo com Geertz (2011) é o que dá sentido ao seu viver, pois a cultura constitui-se no vivido cotidianamente, significando ação humana, simbolismo. Assim, a percepção que a comunidade constrói da natureza é resultado de diversos elementos que constituem a cultura, tanto locais, envolvendo a sabedoria popular, quanto globais, que abrangem as influências dos valores da sociedade como um todo.

Em uma perspectiva dialógica, a educação valoriza experiências/vivências prévias, tornando-se um processo dinâmico e significativo ao educando (Freire, 2011). A aproximação com a cultura local e com o conhecimento familiar dos escolares, oportunizada pelas oficinas, contribuiu para a compreensão do contexto e das necessidades desses sujeitos. Contemplar o cotidiano, o vivido, ouvir o outro e perceber as emoções facilitou a aprendizagem dos escolares, de forma significativa.

Portanto, a interface saúde e ambiente precisa ser trabalhada de forma interligada com a cultura dos indivíduos, para estimular a formação do pensamento crítico e favorecer o bem-estar humano e ambiental.

O diálogo também despertou a consciência de que podem ser os novos talentos do futuro, como revelado pelos discursos:

“O Projeto Novos Talentos é para educar a gente. É para a gente crescer e ajudar outras pessoas. Elas precisam de nós, pois somos o futuro delas. Quando a gente crescer, podemos ajudar os outros a pensar." (Bergamoteira, texto escrito)

"As oficinas significaram para mim aprendizado e futuro. Para falar a verdade esses foram os mais importantes dias da minha vida." (Ginseng, texto escrito)

Trabalhar a partir da realidade vivenciada pelos educandos contribuiu para os mesmos refletirem sobre as questões sociais e ambientais que os cercam e o potencial de modificar este contexto. É nessa dimensão que visualizamos a importância da educação, que tem o potencial de despertar valores e transformar atitudes com criticidade. 
Os diálogos gerados instigaram os escolares a se percebem como atores sociais comprometidos com o contexto socioambiental. Também com a capacidade de transformar a realidade de sua comunidade. Eles demonstraram a preocupação com os riscos que a destruição dos recursos naturais causa à sociedade e às futuras gerações.

Nutrir o processo educativo por meio das experiências culturais fortalece o exercício da liberdade em um duplo movimento de ação-reflexão, que aponta caminhos para a promoção do viver saudável (Freire, 2011).

\section{CONSIDERAÇÕES FINAIS}

Conhecer o significado gerado pelos escolares às discussões sobre cuidado com a saúde e a natureza permitiu constatar o potencial de metodologias participativas - a exemplo de oficinas - no despertar de novas visões de mundo, ressignificando o sentido do cuidado.

Os discursos dos educandos revelaram a consciência dos reflexos da ação humana no ambiente e o compromisso social de cada um com as futuras gerações e com o planeta. A noção de cuidado produzida por eles revela uma dimensão integral, visto que passa pelo entendimento da relação dinâmica do ambiente com os seres vivos dele dependentes.

O diálogo construído despertou nos escolares a criticidade sobre o contexto atual e futuro da sua comunidade. Na posição de protagonistas desse meio, sentem-se responsáveis pela manutenção das condições de vida. Isso mostra que a aprendizagem baseada na ação e no vivido contribui para a incorporação de atitudes críticas e coletivas, que ressignificam o cuidado.

Ao colocar em comunicação o significado de cultura de Geertz e a perspectiva educacional de Freire, foi possível conhecer a realidade

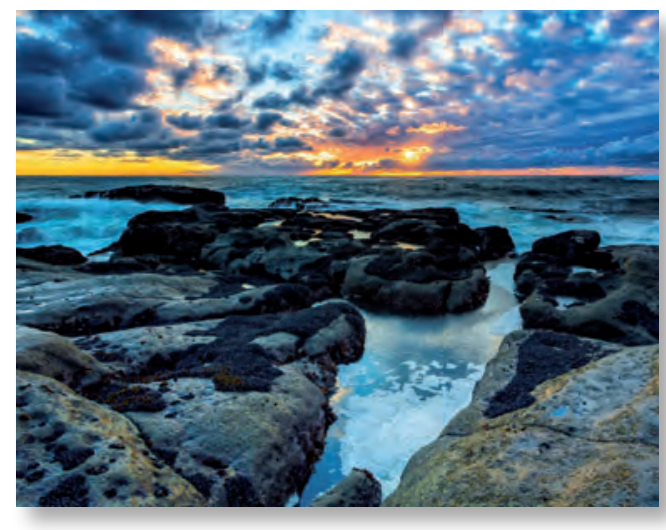

cultural dos educandos e estabelecer uma relação que modificou tanto o pensamento dos escolares quanto dos pesquisadores, ambos, atores do processo educativo.

Novas pesquisas de interesse emancipatório são sugeridas, ou seja, que tenham a intenção de fomentar o pensamento crítico e reflexivo com os sujeitos, onde todos são atores, aprendem e ensinam. Explorar referenciais teórico-metodológicos participativos potencializa a construção de uma ciência social e prática, comprometida com a transformação de realidades.

\section{REFERÊNCIAS}

- Amaral, I.A (2016). Educação ambiental e ensino de ciências: uma história de controvérsias. Pro-Posições, 12(1), 73-93.

- Alves, H. S., Souza, A. D. M., \& Sawaki, R. (2015). Implantação de horta orgânica: educando com a horta escolar na escola de ensino integral Frei Fabiano Merz em Santarém. Cadernos de Agroecologia, 10(3), 55-68.

- Boff, L (2012). O Cuidado Necessário - na Vida, na Saúde, na Educação, na Ecologia, na Ética e na Espiritualidade. São Paulo: Editora Vozes.

- Ceolin, S. (2012). O processo de educação em saúde a partir do diálogo sobre plantas medicinais: significados para escolares. (Dissertação de mestrado não publicada). Programa de Pós-graduação em Enfermagem, Universidade Federal de Pelotas: Pelotas/RS/Brasil. Recuperada 


\section{Cultura de las Cuidados}

de: http://wp.ufpel.edu.br/pgenfermagem/files/2015/10/ 3295c76acbf4caaed33c36b1b5fc2cb1.pdf

- Ceolin, S., Mendieta, M. C., \& Ceolin, T., Lopes, A. C. P., Heck, R. M. (2016). Diálogo sobre plantas medicinais: significados de escolares. Cultura de los Cuidados, 45, 98-107.

- Freire, P. (2016). Pedagogia da autonomia: saberes necessários à prática educativa. São Paulo: Paz e Terra.

- Geertz, C. (2011). A interpretação das Culturas. Rio de Janeiro: LTC.
- Lima, S. M. P., \& Miranda, M. H. R (2015). Prática docente, pesquisa e iniciação científica: um olhar para questões ambientais na escola pública. Revista Ambivalências, 3(6), 237-254.

- Minayo, M.C.S. (2015). O desafio do conhecimento: pesquisa qualitativa em saúde. São Paulo: Hucitec.

- Souza, P. D. F. B. S., \& Santos, D. B. (2016). Percepção de alunos sobre a relação saúde e meio ambiente. Revista Cultural e Científica do Unifacex, 14(1), 54-63.

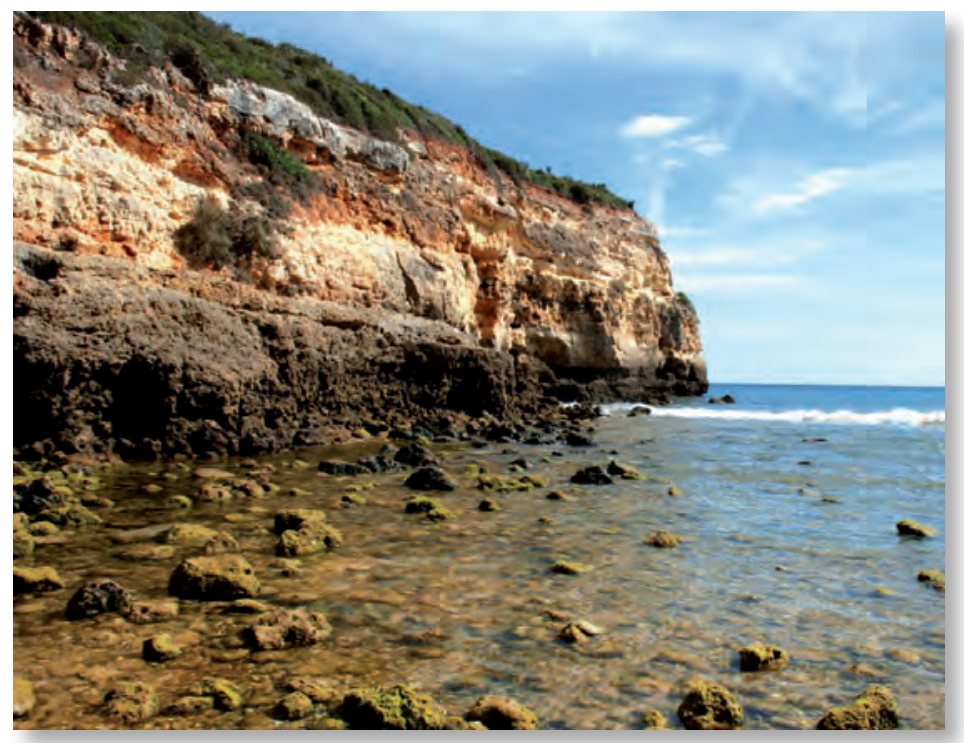

